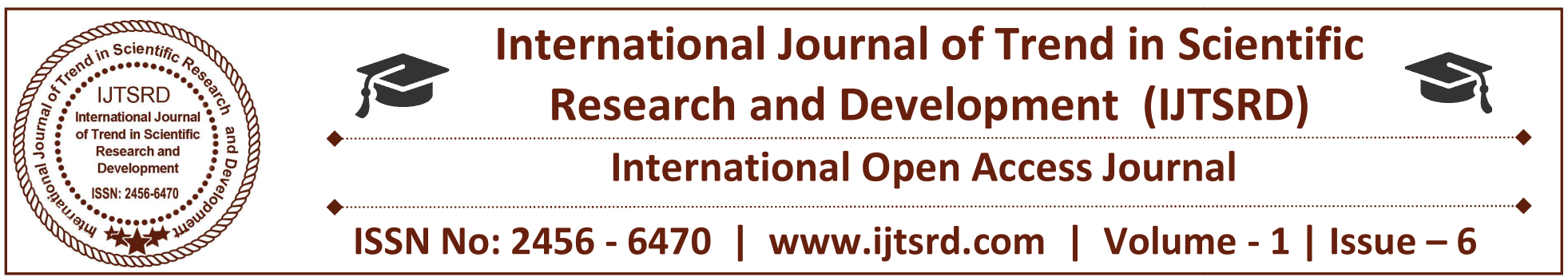

\title{
Modeling of Biodiesel Fuelled Direct Injection CI Engine using CFD
}

\author{
Maulesh H Parikh \\ Dept. of Mechanical Engg., Parul Institute of Engg. \\ and Tech., Vadodara, Gujarat, India
}

\author{
Mori Nirav B \\ Dept. of Mechanical Engg., Parul Institute of Engg. \\ and Tech., Vadodara, Gujarat, India
}

\begin{abstract}
In present years, biodiesel is used as a fuel in internal combustion engine. This study deals with the combustion modeling of CI engine fuelled with Karanja oil as biodiesel. Combustion characteristics like heat release rate, cylinder pressure and rate of pressure rise have been analyzed. CFD code Fluent is used to model complex combustion phenomenon in compression ignition engine. The sub-model like k-e model, Taylor Analogy breakup model and droplet collision model are used. For modeling of in-cylinder combustion, finite rate chemistry and species transport models are used with simplified chemistry reactions. The modeling results were compared with the experimental results. The simulated combustion results are found satisfactory with the experimental results. The major objective of this paper is to study how combustion phenomenon occurred in engine cylinder with the help of CFD and also to understand the effect of biodiesel on CI engine combustion.
\end{abstract}

Keywords: Combustion characteristics, Biodiesel, CFD modelling, simulation

\section{INTRODUCTION}

Due to rising petroleum prices, exhaust emission and global warming have generated an intense interest in developing alternative fuel for petroleum oil. In present years, biodiesel is used as a promising alternative to conventional diesel due to its desirable attributes such as renewable, biodegradable, , sustainable and carbon neutral. Biodiesel can directly replace petroleum diesel and be easily used in diesel engine without the requirement of any major modifications, reducing the country's dependence on imported oil.

Biodiesel produced from either vegetable oil or animal fats consists of long chain mono-alkyl esters derived through transesterification process.

The theoretical models are used in the case of internal combustion engines can be classified into two main groups: fluid dynamic models and thermodynamic models. These models are again classified into two group's namely multi-zone models and single-zone models. Multi-zone models are also called computational fluid dynamics models.

Interdisciplinary and diverse due to powerful modeling tool like CFD. Computational fluid dynamics (CFD) is the analysis of systems involving heat transfer, fluid flow and associated phenomena like chemical reactions with the help of computer based simulation. It constitutes a new approach in research study and development of whole discipline of fluid dynamics. Computational Fluid dynamics plays a strong role as a design as well as research tool. The Computational Fluid dynamics code FLUENT is used to model complex combustion phenomenon in compression ignition engine. The sub models such as Taylor Analogy Breakup (TAB) model and droplet collision model are used for spray modeling. The wall-film model is used to analysis of spray wall interaction. Modeling in-cylinder combustion, finite 
rate chemistry and species transport model is used with simplified chemistry reactions.

\section{PROPERTIES OF FUELS}

There is various types of raw material like pongamia pinnata (karanja), jatropha curcus L, moha, undi, castor, cotton seed, saemuruba etc. Non edible oil seeds as well as various vegetable oils including palm oil, sunflower oil, soybean oil, rapeseed oil and canola oil have been used to produce biodiesel fuel and lubricants. In this investigation, karanja oil is used as raw material for producing a biodiesel. Many researchers studied about the biodiesel and its blends.

Anand Kumar Pandey et al (2011) investigated the effect of karanja oil biodiesel on performance, engine wear and emission of a military 160hp turbocharged CIDI engine. Avinash Kumar Agarwal et al (2013) studied about the performance and emissions of karanja oil and its blends in four stroke single cylinder agricultural diesel engine. The physical properties of fuel found are as follows.

\section{CFD MODELING}

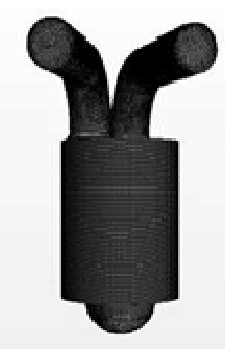

Fig. 1: Meshed Combustion Chamber

Computational fluid dynamics becomes the powerful tool for analyzing the fluid flow, heat transfer, etc of the system. We can easily create the model of any system and can analyze it using different function of CFD. We can visualize many things with the help of computer based simulation CFD.

Jacob George et al (2013) studied about STARCD software to simulate diesel combustion. The geometry has been modelled and meshed in pre-processor GAMBIT. The combustion chamber is a bowl in piston type, which is having a hemispherical groove at the piston top surface. The geometry has been modelled at $180^{\circ}$ crank position (BDC position). In order to obtain realistic simulations, computation must include true combustion geometry with inlet and exhaust valve positions. Hence a 3D model of the combustion chamber he has been developed for the Kirloskar TV1 engine.

H. Sushma (2013) studied about the effect of different piston configurations on in-cylinder flow. Four stroke single cylinder direct injection diesel engine is used for study. For obtaining swirl intensity helical-spiral combination inlet manifold is used. Increase in swirl intensity results in better mixing of fuel and air. Swirl velocities in the charge can be substantially increased during compression by suitable design of the piston. She studied about the effect of different piston configuration on air motion and turbulence inside the cylinder of a direct injection diesel engine. It is carried out using Computational Fluid Dynamics code Fluent 13. Three dimensional models of the pistons, cylinder, and the manifolds is created in CATIA V5 and meshed using the pre-processor Hypermesh 10.0.

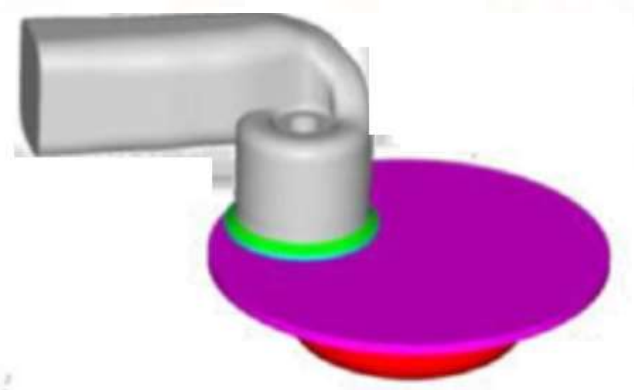

\section{Fig. 2: CFD Model of IC Engine Piston at TDC}

\section{EXPERIMENTATION}

Experiment is carried out on direct injection CI engine by using biodiesel as a fuel. Biodiesel and its blends are considered most promising and suitable fuel for diesel engine. The properties of biodiesel are found nearly similar to that of diesel. Many researchers have experimentally evaluated the performance characteristics of conventional diesel engines fuelled by biodiesel and its blends. The engine is coupled to a DC dynamometer and all the experiments were carried out at a constant speed of $1400 \mathrm{rpm}$. Crankangle-resolved in-cylinder pressure and the diesel injection pressure were measured. A computer interfaced piezoelectric sensor, of range 145 bar was used to note the in cylinder pressure. Using a digital data acquisition system, pressure signals were obtained at one-degree crank angle intervals. The average pressure data from 100 consecutive cycles are used for calculating combustion parameters. 
Combustion parameters are obtained by using special software. The special software stores the data of volumes and pressures corresponding to a particular crank angle location for plotting the P- $\theta$ and $\mathrm{P}-\mathrm{V}$ curves. The Software also provides the facility of analyzing the combustion data such as the peak pressures, Rate of Heat-Release and stores it separately for analysis in the computer system.

\section{A. Combustion Analysis:}

Jacob George et al (2012) carried out performance, combustion and emission tests on a four stroke, single cylinder, naturally aspirated, water cooled Kirloskar diesel engine having a power capacity of $3.5 \mathrm{~kW}$ at different injection timing. It is connected to an eddy current dynamometer for loading. Temperature and pressure sensors are installed at the necessary locations in the test setup. The temperature sensors measure temperatures at inlet $\&$ outlet of water jacket; calorimeter water and calorimeter exhaust gas. It is also provided with pressure sensors to measure combustion pressure inside cylinder and also to measure the fuel line pressure during injection.

Mohamed F. Al-Dawody and S. K. Bhatti (2013) carried out theoretical analysis on a naturally aspirated, water-cooled, four stroke, single cylinder, direct injection diesel engine fuelled with Soybean methyl ester at different compression ratio. They observed different combustion and performance characteristics at different compression ratio. Avinash Kumar Agarwal et al carried out the experiment on performance, emission and combustion characteristics of biodiesel fuelled diesel engine. Karanja oil and mineral diesel blends were evaluated in a four stroke, single cylinder compression ignition engine operated at constant speed of $1500 \mathrm{rpm}$. Heat release rates for different blends of karanja oil with mineral diesel at different load are shown in Fig

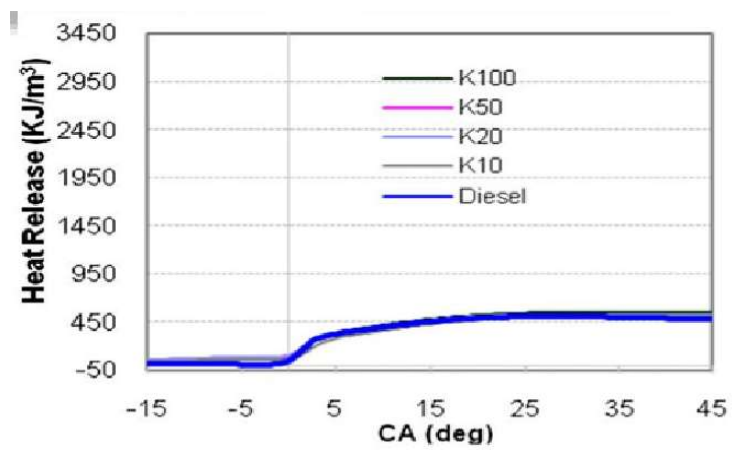

Fig. 3: Cumulative heat release vs. crank angle diagram for $0 \%$ rated load

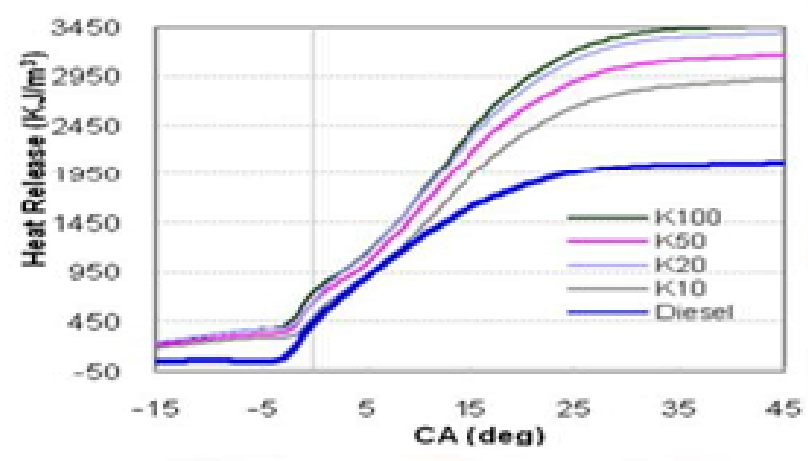

Fig. 4: Cumulative heat release vs. crank angle diagram for $100 \%$ rated load

Venkata Ramesh Mamilla et al (2012) carried out the experimental investigation on direct injection compression ignition engine fuelled with blends of karanja methyl esters with diesel. They observed the following combustion characteristics at various load condition shown in fig.

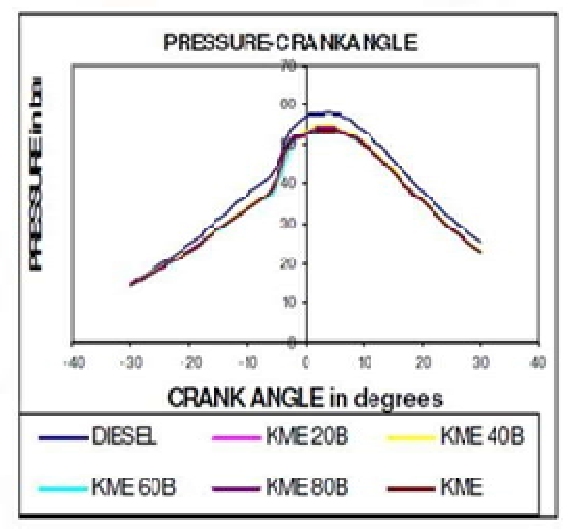

Fig. 5: pressure rise at no load

\section{CONCLUSIONS}

The overall analysis has shown that biodiesel has potential as an alternative fuel and can be used in conventional internal combustion engines. The properties of biodiesel are found similar to that of diesel. It can be seen that computational fluid dynamics plays a strong role as a design as well as research tool in combustion analysis of internal combustion engine. The CFD code FLUENT has been used to simulate the combustion characteristics of direct injection diesel engine. CFD fluent is the powerful software for analyzing fluid flow, heat transfer and combustion phenomenon of the system. The model consisting of sub models includes droplet 
collision, spray, wall film and combustion model with species transport and finite rate chemistry. It becomes easy to model and analyze combustion phenomenon of CI engine with the help of CFD. The CFD modeling can be the reliable tool for modeling combustion of internal combustion engine.

\section{REFERENCES}

[1] Anand Kumar Pandey and M R Nandgaonkar, "Experimental Investigation of the Effect of Esterified Karanja Oil Biodiesel on Performance, Emission and Engine Wear of a Military 160hp Turbocharged CIDI Engine", Proceedings of the World Congress on Engineering 2011 Volume III, WCE 2011, July 6 - 8, 2011, London, U.K.

[2] Avinash Kumar Agarwal, "Experimental investigations of performance, emission and combustion characteristics of Karanja oil blends fuelled DICI engine", Elsevier, Renewable Energy 52 (2013) pp.283-291.

[3] B. Rajendra Prasath, P. Tamil Porai, Mohd. F. Shabir, "Two-zone modeling of diesel / biodiesel blended fuel operated ceramic coated direct injection diesel engine", International Journal Of Energy And Environment, Volume 1, Issue 6, 2010 ppe1039-1056.

[4] H.Sushma, "CFD modelling of the in-cylinder flow in direct injection CI engine", International Journal of Scientific and Research Publications, ISSN 2250-3153, Volume 3, Issue 12, December 2013.

[5] Jacob George et , "Experimental Investigation And Modelling Of A Four Stroke Single Cylinder Di Diesel Engine Under Various Injection Timings", International Journal Of Engineering Science And Technology (IJEST), Vol. 4 No.08 August 2012.

[6] Laukik P. Raut, " Computer Simulation of CI Engine for Diesel and Biodiesel Blends", International Journal of Innovative Technology and Exploring Engineering (IJITEE) ISSN: 22783075, Volume-3, Issue-2, July 2013.

[7] Mohamed F. Al-Dawody and S. K. Bhatti, "Theoretical modeling of combustion characteristics and performance parameters of biodiesel in DI diesel engine with variable compression ratio" International Journal Of Energy And Environment, Volume 4, Issue 2, 201 